\title{
TERRITORIALIDADE DA EDUCAÇÃO: AS ESCOLAS PÚBLICAS NAS ÁREAS CENTRAIS DE SÃO PAULO
}

\author{
Gilberto Cunha Franca*
}

Resumo: O objetivo deste artigo é discutir a territorialidade da educação, como parte do conjunto das infraestruturas sociais. Ele analisa, mais especificamente, a situação de uma antiga escola localizada em Pinheiros, no Município de São Paulo. Trata-se da experiência dramática desta escola diante das transformações metropolitanas e educacionais, e que têm levado ao esvaziamento e ao fechamento de dezenas de estabelecimentos de ensino nas áreas mais centrais e valorizadas deste Município. O texto procura explicar como as forças sociais imbricadas em diferentes escalas geográficas evoluíram, e se enfrentaram, na configuração deste problema. Expõe-se, portanto, aqui, um estudo geográfico da educação e as tentativas de sujeitos dispersos de uma comunidade para preservar sua antiga escola.

Palavras-chave: urbanização, políticas educacionais, lugar, escola pública, cidade.

\section{TERRITORIALITY EDUCATION: THE PUBLIC SCHOOLS IN CENTRAL AREAS OF SÃO PAULO}

\begin{abstract}
This paper aims to discuss the territoriality of education as part of an ensemble of social infrastructures. It examines more specifically the situation of an old school located in Pinheiros (neighborhood of the city), in São Paulo. The dramatic experience of this school before the metropolitan and educational changes is analyzed, and how that has led to the evacuation and closing of dozens of schools in more central and valued areas of the city. The text seeks to explain how social forces embedded in different geographical scales evolved, and faced each other, setting up this problem. It explains, therefore, a geographical study of education, and the attempts from specific subject spread in their community to preserve their old school.
\end{abstract}

Key Words: urbanization, education policy, district, public school, city.

\section{Introdução}

Este estudo traz uma discussão sobre a escola pública e seu lugar no processo de metropolização. A análise particular das escolas públicas inscritas nas áreas mais valorizadas da cidade foi estimulada pela identificação do seu esvaziamento e do fechamento de dezenas destes estabelecimentos de ensino.

Paradoxalmente, isto ocorre onde aparecem os melhores resultados de desempenho da rede pública estadual no Município de São Paulo. O que configura um problema, que os indicadores de desempenho não conseguem e não procuram explicar.

No plano teórico, esta pesquisa se insere no conjunto complexo das infraestruturas sociais e suas territorialidades (HARVEY, 1990). Na análise geográfica da educação foi explorada a dimensão local e cotidiana, sobre a qual recaem as transformações projetadas nas escalas mais amplas do território ${ }^{1}$.

\footnotetext{
1 Portanto, não se trata de uma abordagem do ensino de geografia, ainda que as condições geográficas sobre as quais as práticas
}

* Departamento de Geografia, Geografia Humana. Email: gfranca@usp.br 
Portanto, privilegia-se o nível urbano e mais especificamente o contexto do lugar, onde as transformações gerais adquirem toda vivacidade e revelam as novas formas de uso do espaço e do tempo. Por este motivo, foi indispensável a utilização da metodologia de análise dos níveis e dimensões da realidade urbana, proposta por Lefebvre (2004). Ela permitiu reconstruir os nexos mais abstratos que contornam o dilema destas escolas que ficaram inscritas nos espaços valorizados da metrópole de São Paulo.

A territorialidade da educação, como algumas pesquisas apontam, exprime oportunidades diferenciadas de inserção social. Mas a questão passa por compreender a produção desta desigualdade espacial. Mais apropriadamente, nossa questão é saber quais forças governaram, ou tiveram proeminência, sobre essa evolução espacial desigual? E que tipo de uso do espaço e do tempo se manifesta nestas escolas públicas nos espaços centrais de São Paulo?

Tentou-se seguir, como método de pesquisa, uma orientação tão bem posta por Harvey (2005, p.11), em procura por

Desvelar algumas das transformações mais profundas que ocorrem sob toda a turbulência e volatilidade de superfície e, dessa maneira, abrir um terreno de debate acerca de como melhor interpretar nossa atual situação e reagir sobre ela.

\section{A TERRITORIALIDADE INFRAESTRUTURAS SOCIAIS}

DAS

Como dito anteriormente, o estudo da educação no nível local relaciona-se com transformações econômicas e políticas nas

pedagógicas se desenvolvem tenham profundas relações com o aprendizado. escalas do território nacional e regional. Harvey (1990, 2005) oferece uma explicação da territorialidade da educação e das infraestruturas sociais (englobando também pesquisa, saúde, lazer) na sua teoria sobre a crise e o ordenamento espacial do capitalismo.

Para o autor, a evolução das infraestruturas sociais, tal como das infraestruturas físicas (transporte, energia, comunicação, etc.), constitui um capítulo destacado na formação e solução das crises econômicas e fiscais do Estado. Segundo sua interpretação, no desenvolvimento geográfico desigual do capitalismo (HARVEY, 1990, p. 406):

A reestruturação periódica da geografia de infra-estruturas sociais geralmente se consegue no curso de uma crise. A desvalorização do capital cristalizado nas infra-estruturas sociais de um lugar específico, e digamos a destruição das formas tradicionais de vida e todas as formas de localismo integradas ao redor das instituições sociais e humanas, se coloca como elemento central da formação e resolução das crises sob o capitalismo.

\section{Limites da Educação no Brasil}

No Brasil, o sistema público de ensino nas últimas duas décadas esteve condicionado pelos limites do novo regime econômico. Sob crescimento e força da acumulação financeira, os gastos sociais e produtivos foram contidos (BRUNO, 2009), ao mesmo tempo em que o sistema educacional era submetido, através do Estado, a reestruturações produtivas, para lidar com as metas fiscais, a vulnerabilidade 
e crise do novo regime de acumulação (GONÇALVES, 2006).

Tal fato resultou praticamente no congelamento dos gastos com educação em relação ao PIB nos dois últimos governos (CASTRO, 2007), variando da média de 4,0\% do PIB no governo de Cardoso, entre 1995 a 2002, para 4,3\% no Governo Lula, de 2003 a 2009 (INEP, 2011) 2.

O aumento de 0,3\% em relação ao PIB, no período do último governo ${ }^{3}$, sinalizou uma pequena alteração. Porém, de conjunto, o modelo neoliberal atuou para conter os gastos educacionais, apesar do discurso em torno da educação. Mas, ao mesmo tempo, foi sob este modelo que o sistema educacional público sofreu importante mudança, através de reestruturações e adequações federais e estaduais.

\section{Reestruturação Educacional Paulista}

No estado de São Paulo, foi realizada, a partir de 1995, a reestruturação do sistema de ensino, como parte da reforma do Estado, compartilhando metas do Banco Mundial. Ganhou força a ideia de que os problemas educacionais relacionavam-se com 0 problema de gestão, daí a ênfase na reutilização da infraestrutura existente, como suficiente para expandir as matrículas e melhorar a qualidade do ensino público (ADRIÃO, 2006).

Segundo Adrião, o ajuste neoliberal da educação paulista se deu através da reforma e racionalização da rede administrativa e das mudanças no padrão de gestão escolar. Envolveram a municipalização

\footnotetext{
2 Segundo Castro (2007, p.870), "[...] este congelamento: Reflete opção de política econômica que tem levado à imensa transferência de renda do lado real da economia para o financeiro - e que se processa mediante apropriação de parcela expressiva do gasto público".

${ }^{3}$ Nos 8 anos do Governo Lula, a média do PIB foi de $4 \%$, enquanto nos dois mandatos do Governo de FHC a média foi de 2,3\% (IPEA, 2011).
}

do ensino, a reorganização das escolas e os sistemas de avaliação externos.

O ensino fundamental, através de mudanças na legislação federal, passou por um processo de municipalização (ARELARO, 1999). A dificuldade maior tem recaído sobre os municípios menores, na garantia da qualidade do ensino fundamental, além de ter se acentuado a fragmentação entre as esferas de governo (municipal, estadual e federal) no atendimento do ensino público como um todo (PINTO, 2010).

Uma medida central na reestruturação da rede estadual foi 0 Programa de Reorganização da rede de ensino (SEE, 1995). A reorganização significou uma revirada na geografia da maior rede pública: alunos e professores foram redistribuídos; turnos e escolas foram extintos, algumas foram municipalizadas. Foram registradas manifestações de pais, especialistas e trabalhadores da educação paulista (AÇÂO EDUCATIVA, 1996). Porém, como em geral, prevaleceu a dificuldade de mobilização comunitária, civil e principalmente de classe ${ }^{4}$.

Merece destaque uma terceira medida da reestruturação da rede estadual: o sistema de avaliação externo. As primeiras experiências de avaliação externa começaram no início dos anos 90, chegando atualmente à forma do IDESP ${ }^{5}$. Com esta medida, cria-se um ranking anual entre as escolas, que varia de 0 a 10 pontos. O IDESP tem frustrado as

\footnotetext{
4 Como disse Harvey (2007, p. 1), "[...] el neoliberalismo es sobre todo un proyecto para restaurar la dominación de clase de sectores que vieron sus fortunas amenazadas por el ascenso de los esfuerzos socialdemócratas en las secuelas de la Segunda Guerra Mundial".

5 Índice de Desenvolvimento da Educação do Estado de São Paulo. O IDESP leva em conta a nota do Sistema de Avaliação de Rendimento Escolar do Estado de São Paulo (SARESP) mais o fluxo escolar (taxa de aprovação dos alunos e idade série). SARESP. Disponível em: $<$ http://saresp2009.edunet.sp.gov.br/pdf/02 Apre sentacao final.pdf>. Acesso em 30/03/2010.
} 
expectativas a cada ano, com resultados que apontam a qualidade crítica da escola pública e a desigualdade espacial do ensino ${ }^{6}$.

\section{A METROPOLIZAÇÃo E ADEQUAÇÃo ESPACIAL dAS ESCOLAS PÚBLICAS de SÃo PAULO}

A geografia atual da educação em São Paulo reflete sua dimensão metropolitana, com problemas intensificados pelas transformações urbanas da década de 1990 em diante.

A metropolização de São Paulo, entretanto, é um processo de longa duração, aqui dividido em dois momentos. O primeiro refere-se, propriamente, à passagem da cidade à metrópole, numa explosão induzida pela indústria, sob forte concentração populacional. Numa explicação da metamorfose do fenômeno urbano de São Paulo, Seabra (2004, p. 271) diz que:

A Cidade de São Paulo chegou a sua mais exuberante forma nos anos 1950 quando, nitidamente integrada por uma coroa de bairros, foi ficando imersa num processo de implosão-explosão para as periferias. Formou-se uma enorme extensão de urbanização contínua e os moradores, já então, metropolitanos, viveram novas experiências de espaço e de tempo. (grifos do original)

O momento atual da urbanização prossegue como reprodução da metrópole (CARLOS, 2004). A metrópole se reestrutura sob hegemonia financeira, redefinindo sua estrutura urbana. Melhor dizendo, São Paulo experimenta transformações, ampliando e redefinindo as relações centro e periferia.

Ressalta-se aqui a dinâmica demográfica e social dos espaços metropolitanos. Enquanto nas periferias o crescimento populacional segue positivo em quase toda sua extensão, inversamente, nas áreas internas, ocorrem perdas populacionais consideráveis. O que pode ser visualizado no mapa 1, de variação da população, entre 1991 e 2000.

O fenômeno da diminuição ocorre mais intensamente, justamente, nas áreas mais valorizadas e internas da metrópole. Mas isto fica mais evidente no quadrante Sudoeste do Município de São Paulo, onde foram experimentados os novos modelos de urbanização, pelas investidas da indústria imobiliária e das grandes corporações (CARLOS, 2004; FIX, 2007; BERNARDES, 2001).

Foram condensadas ali as virtudes da urbanização. Os moradores convivem com melhores possibilidades de circulação, de deslocamentos menos degradantes, de acesso ao trabalho, à informação, ao conhecimento, ao lazer. Tanto que se concentra, nestes espaços internos da metrópole, boa parcela dos equipamentos culturais.

No despovoamento das áreas centrais, o impacto foi maior sobre as camadas populares (TORRES, 2005, FRANCA, 2010). Acentua-se com isto, na reestruturação metropolitana dos anos 90, a tendência que despontava, de concentração das classes médias e altas, e de exclusividade da centralidade da metrópole.

Nas periferias crescem explosivamente as populações de baixa renda, mas registram-se certas diferenciações, com o crescimento das classes de renda mais alta, moradores principalmente dos condomínios residenciais, na periferia da metrópole.

\footnotetext{
${ }^{6}$ O que é mais grave no caso paulista: reproduzindo imensas desigualdades educacionais, conforme matéria a seguir: Maior desigualdade escolar é em São Paulo. Folha de São Paulo, Cotidiano C3, 24 de dezembro de 2007.
}

* Departamento de Geografia, Geografia Humana. Email: gfranca@usp.br 


\section{Mapa 1 - Variação da população entre 1991 a 2000 Município de São Paulo, por distrito}

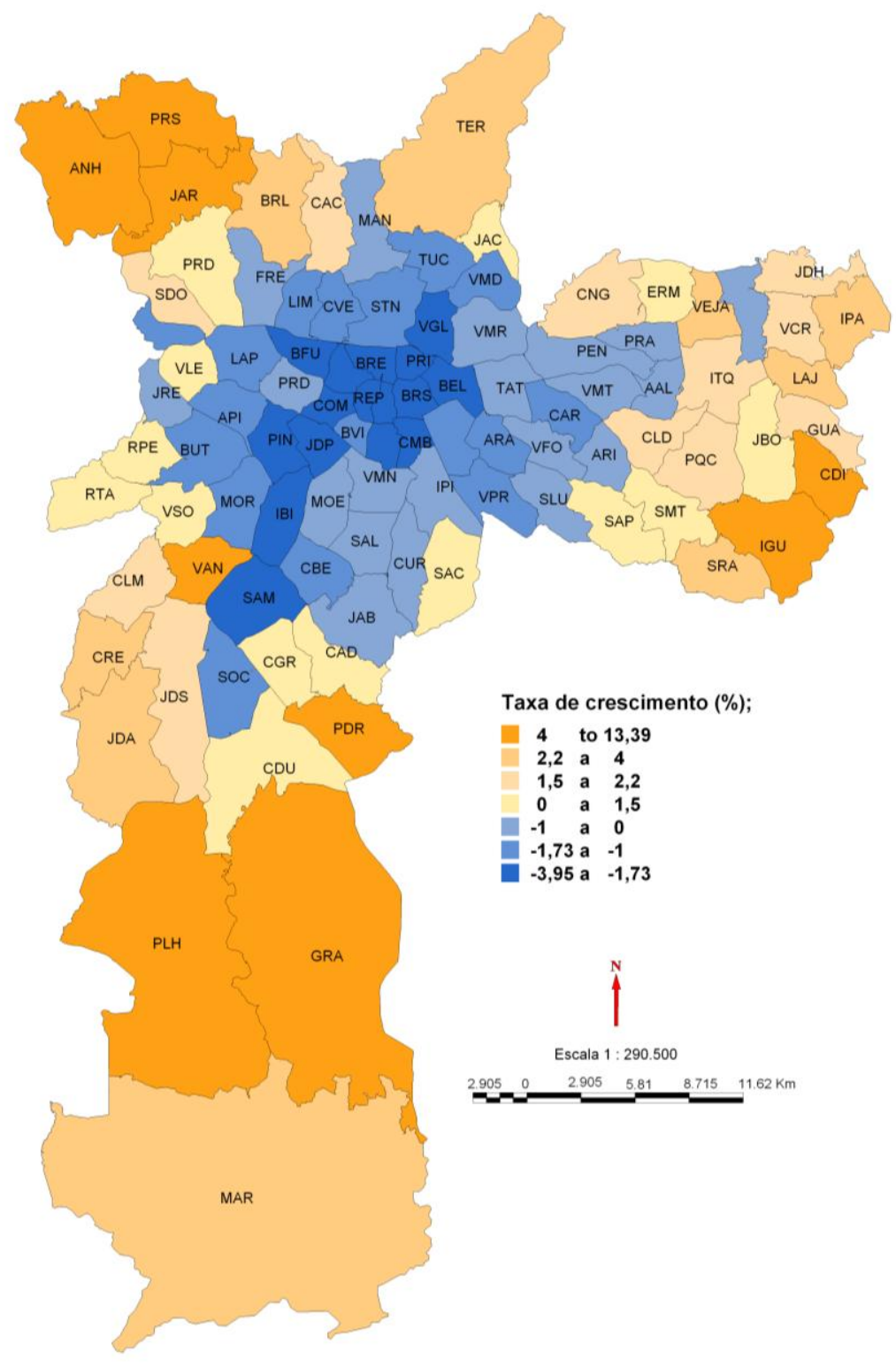

Fonte: SMDU, 2010. Elaborado pelo autor

\section{Redistribuição espacial das escolas públicas no Município de São Paulo}

A espacialidade da escola pública relaciona-se, portanto, com as transformações urbanas e educacionais, propriamente ditas. Esta relação foi captada na pesquisa a partir da redistribuição espacial dos alunos que ocorreu, principalmente, no processo da reorganização das escolas. Como se vê no mapa 2, nos espaços periféricos de São Paulo as matrículas seguiram crescendo nas escolas públicas. Porém, pela primeira vez, desponta a diminuição das matrículas na área interna do Município. 


\section{Mapa 2 - Variação do número de alunos e extinção das escolas públicas (1995 - 2007) Município de São Paulo, por distrito}

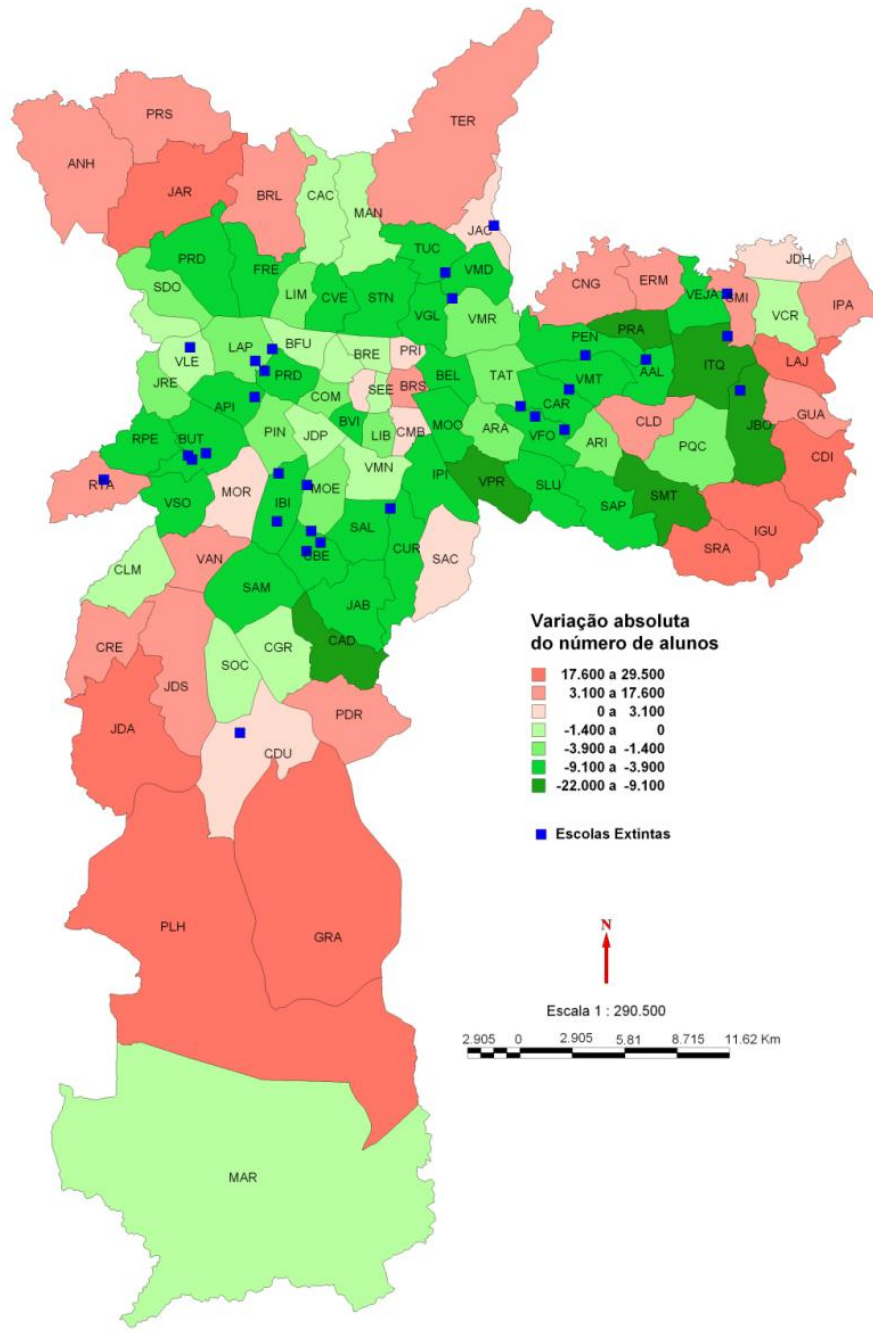

Fonte: SEE - CIE. Cadastro de Escolas do Município de São Paulo, em 1995 e 2007. Elaborado pelo autor

Nas periferias, maior crescimento foi observado nos distritos de Anhanguera, na Zona Norte; Lajeado, na Zona Leste; e em Parelheiros, na Zona Sul. Mas não deixa de chamar à atenção a diminuição expressiva em determinadas áreas da periferia consolidada, como Itaquera e José Bonifácio, na Zona Leste. Sinais das alterações socioespaciais na periferia no período analisado.

Nas localidades mais centrais ocorre a diminuição do número de matrículas nas escolas públicas. É o caso do Distrito de Alto de Pinheiros, da Barra Funda, Belém, Bela Vista. Mas se observa o crescimento em áreas do antigo centro, como no Distrito da República, do Brás, Cambuci e Pari. Evidências da presença ainda expressiva da população de renda mais baixa nos espaços centrais da metrópole.

A pesquisa identificou a predominância das matrículas no ensino privado provada em boa parte dos distritos onde as matrículas na escola pública diminuíram. Além disso, no período analisado, impressiona a velocidade da expansão do ensino privado em direção aos espaços periféricos, em lugares inexistentes até pouco tempo. 
$\mathrm{Na}$ reorganização das escolas também dezenas delas foram extintas. 0 fechamento expressa os novos conteúdos dos lugares centrais da metrópole e a procura do Estado em manter a expansão periférica do ensino público. Entre 1995 e 2007, a Secretaria de Estado da Educação (SEE) fechou 34 escolas, apenas no Município de São Paulo. Como se vê no mapa 2, grande parte das escolas desativadas novamente coincide com as localidades que mais se valorizam e perdem população, com intensa remoção de pobres.

O fechamento revelou também 0 interesse dos órgãos públicos pela reutilização dos estabelecimentos de ensino para atividades pedagógicas, administrativas e para unidades da Polícia Militar. Contudo, aparecem casos onde é claro o interesse do setor imobiliário pelo terreno das escolas públicas cravadas em espaços raros e caros da metrópole.

A Escola Estadual (EE) Prof. José Alves de Camargo, na Vila Formosa, foi desativada para a construção de condomínio residencial. O terreno da EE Martim Francisco, na Vila Nova Conceição, esteve para ser permutado com uma empresa imobiliária. Ocorrem manifestações contra a venda de um quarteirão no Itaim Bibi, que pode levar à desativação da EE Prof. Ceciliano José Ennes e da Escola Municipal de Educação Infantil (EMEI) Aristide Setubal.

O paradoxo é que, nos espaços onde ocorre a perda de matrículas e o fechamento de escolas, o desempenho médio é mais alto no Município de São Paulo7. A nota média do IDESP destas escolas públicas

\footnotetext{
7 Cabe destacar o caso paradigmático da EE Alberto Torres, no Butantã. A tentativa de fechamento ocorreu em 2010, mesmo ano em que a Escola obteve melhor nota no IDESP. A divulgação na imprensa deste paradoxo levou à queda da Diretora de Ensino da região CentroOeste.
}

varia de 2 a 3 vezes mais que as notas dos alunos das escolas públicas nos espaços periféricos ${ }^{8}$. O fundamento local de sua diferenciação é o mesmo que produz seu esvaziamento.

Estas escolas ficaram aquém das expectativas da maioria de seus moradores, abrindo espaço para as instituições privadas de ensino, por responder melhor à sua reprodução social e cultural. Deslocadas, são atropeladas pela reestruturação produtiva e passam por disputas para redefinir seu uso.

\section{EE. PROF. ANTÔNIO ALVES CRUZ: ESCOLA DE PASSAGEM}

Esta seção aborda os acontecimentos recentes envolvendo o EE. Prof. Antônio Alves $\mathrm{Cruz}^{9}$, no curso da reestruturação urbana e educacional. Portanto, chega-se ao nível do lugar e do cotidiano, na abordagem da geografia da escola pública.

\section{O "lugar" da Escola}

O entorno da Escola é sobreposto por frações do espaço altamente valorizado, refletindo as transformações urbanas dos anos 90. A estrutura adensa-se com a verticalização de escritórios e das torres residenciais que vêm de Perdizes, e seguem por Vila Romana, Vila Leopoldina, Pinheiros e principalmente o vetor Sudoeste.

Neste espaço interno metropolitano, concentraram-se os serviços modernos de São Paulo, dos serviços financeiros aos serviços pessoais. As obras de circulação de pessoas, de informação e de dinheiro são incorporadas no circuito de valorização imobiliária, criando possibilidades exclusivas de trabalho, moradia e consumo.

\footnotetext{
8 "Região Centro-Oeste é a melhor na capital". $O$ Estado de São Paulo, São Paulo, Caderno Vida \& Educação, 19 de março de 2009.

9 Utilizaremos a partir daqui apenas Alves Cruz ou Escola, com letra maiúscula.
} 
As intervenções urbanas vêm removendo antigos espaços industriais, bairros, favelas, criando frações homogêneas num espaço ainda marcado por diferenciações. O conjunto diferenciado se apresenta como melhor região de São Paulo para morar, segundo um conjunto de indicadores de qualidade de vida ${ }^{10}$.

Porém, esta qualidade se restringe a um número cada vez menor de moradores. Isto porque a diminuição da população foi de $15 \%$ entre 1991 e 2000 entre os distritos da Lapa, Perdizes, Alto de Pinheiros, Jardim Paulista, Pinheiros e Consolação (SMDU, 2009). Algo que contrasta com a contínua explosão nas frentes de expansão urbana.

\section{A reestruturação produtiva atinge a escola}

Entre as transformações da rede pública nos anos 90, o cancelamento do Programa da Escola Padrão e a diminuição dos alunos matriculados afetaram particularmente o Alves Cruz.

Com o fim do Programa da Escola Padrão, perdeu-se a condição de trabalho que permitia ao professor mais tempo de atividade pedagógica que, por sua vez, permitia maior permanência na Escola. É o que se percebe na fala Professora Sônia ${ }^{11}$,

A gente usou bem o fato de ser escola padrão. Tinha algumas diferenças que eu consegui entender quando trabalhei em outra escola padrão. É assim, no Alves, a gente dava 28 aulas e

\footnotetext{
10 "São Paulo, 454 anos. Região de Pinheiros é a melhor de São Paulo". Folha de São Paulo, São Paulo, Especial C1, p.6, 26/01/2008. Nesta reportagem especial das comemorações da cidade de São Paulo, a região da subprefeitura de Pinheiros ficou em primeiro lugar entre diversos indicadores de educação, saúde, transporte, violência.

${ }^{11}$ Os nomes dos professores são fictícios.
}

ganhava por 41. Mas você tinha que ficar na escola, e a gente ganha $30 \%$ a mais de salário por dedicação exclusiva, se não tivéssemos outra escola, ou outro trabalho. Era uma proposta muito interessante e achava que era bem legal, porque a gente levava muito a sério nosso HTP [Hora de Trabalho Pedagógico].

\section{Outros} aspectos também diferenciavam as Escolas Padrão, deixando a maior parte da rede em condição desigual. Motivo de crítica, inclusive, de especialistas, sindicatos e trabalhadores da educação. Porém, o fim do programa equalizava por baixo, retirando alguns "privilégios" destas escolas. Tal como ocorreu no Alves Cruz, com a extinção do Programa, o professor teve que assumir mais aulas, inclusive em outras escolas da rede estadual, para completar sua jornada de trabalho.

A escola perdia com isto algumas das condições que permitiram contornar a deterioração salarial nas décadas anteriores. O mais grave é que isto coincidiu com a diminuição acelerada das matrículas, cujo impacto foi a transformação de uma escola com tradição de permanência do professor para uma escola com alta rotatividade.

Entre 1995 e 2007, a região em torno da escola perdeu $37 \%$ das matrículas (SEECIE, 1995, 2007). Importante considerar, neste esvaziamento das escolas centrais, tanto a diminuição demográfica quanto a participação do ensino privado, que passa a representar $70 \%$ entre os seis distritos que contornam a escola.

No Alves Cruz, a perda de alunos foi muito mais acentuada ainda. Em 1995, a 
escola tinha 1.263 alunos matriculados no Ensino Médio e já em 2000 tinha apenas 577 alunos, perdendo $55 \%$ das matrículas. Foi um processo implosivo que levou à desarticulação dos vínculos escolares, com o encerramento do período da tarde, a saída de professores e de diretores. Como ocorreu com a professora Maria Tereza:

No final dos anos 90 começaram com esta coisa de que a escola ia fechar, ia fechar. Eu saí daqui do Alves Cruz em 2000, justamente porque a escola estava diminuindo, diminuindo e eu queria ampliar minha jornada, porque estava nos meus últimos anos de aposentadoria e não conseguia, o noturno ia fechar, só tinha duas salas, um no segundo e outra no terceiro, o que significava que no ano seguinte só iria ter o terceiro.

Neste período registrado, acentua-se a degradação das relações sociais com ocorrências policiais, uso de drogas e a violência indo pra dentro da escola. Algo difícil de contornar no curso do seu desmanche. A escola parecia mesmo não mais reunir força suficiente para se preservar das contradições urbanas, das adequações institucionais, de seu longo desencontro com este lugar da metrópole.

Neste momento, um grupo de alunos se mobiliza dentro e fora da escola contra o fechamento. Os primeiros aliados foram alguns ex-alunos, muitos dos quais pelo destaque que alcançaram em suas profissões ${ }^{12}$. Vasconcellos (2004) ressalta a importância destas personalidades para evitar seu fechamento, não só pela criação de rede de ex-alunos, mas também pelas atividades que passaram a ser desenvolvidas na escola por outras instituições civis e pelo próprio Estado.

12 O movimento atrairia também a atenção de exprofessores e do primeiro diretor Ari Resende, que esteve na escola da sua criação até 1975.
A mais importante destas instituições foi a Associação Fênix, criada em 2001. A ONG passou a ter muita influência no interior da escola, através de seus projetos complementares, realizados à tarde, quando não há aula. Aos sábados ocorre o ensaio do maracatu, que atrai centenas de jovens. Este projeto, criado em 2003, no interior da ONG, tem agora um curso autônomo, e fala-se na sua institucionalização em associação civil.

A escola passou a ter oficinas de músicas, de grafite, aulas de japonês, fabricação de sabonete, de velas, e uma variedade de atividades culturais. Vasconcellos, em sua pesquisa, identifica a influência destes projetos no contato dos alunos com o mundo do trabalho, assim como o envolvimento deles, devido ao caráter prático e à linguagem mais próxima de sua realidade sociocultural.

Entretanto, destaca que os projetos pouco influíram no currículo formal da escola e mesmo na melhora das relações entre alunos e professores, podendo até ter explicitado os estranhamentos. Isto se explica em parte pelo convívio descoordenado e fragmentado entre o ensino regular e seus sujeitos sociais, e as novas atividades, integrantes e interesses que passaram a habitar a escola ${ }^{13}$.

Nesta mudança substancial da vida escolar, os cursos regulares e os antigos personagens, como os professores, perderam muito sua centralidade. Isto porque a entrada dos novos personagens ocorria num período em que a desvinculação com a escola aumentava entre diretores, professores e demais funcionários, no curso das

\footnotetext{
${ }^{13}$ Em 2001 a escola passou a oferecer Educação de Jovens e Adultos (EJA), no período noturno. Isto amenizou um pouco a perda dos alunos regulares. Em 2009, foi introduzida a modalidade de ensino de Educação Profissional, pela Secretaria de Estado de Ciência e Tecnologia, aumentando assim o grau de diferenciação no espaço escolar.
} 
adequações produtivas gerais da SEE e da particularidade local do Alves Cruz.

Levantamento realizado na escola comprova uma rotatividade de diretores de 2000 a 2005, entre a crise e a chegada da atual diretora. Isto para uma escola que tinha convivido por mais de 20 anos com uma mesma diretora e, antes dela, com um diretor que permanecera por 15 anos. 0 problema se agravou com a rotatividade de coordenadores pedagógicos, professores e demais funcionários.

Dos 33 professores em 2009, último ano desta pesquisa, 6 eram efetivos do Alves Cruz, 9 eram efetivos de outras escolas e completavam sua jornada nesta Escola, totalizando 15 efetivos, professores concursados. Os outros 18 professores eram temporários. Destes 33 professores, apenas 12 tinham lecionado no Alves Cruz no ano anterior. Em entrevista, disse Antônio, professor temporário do Alves Cruz,

[...] provavelmente no meio do ano eu rodo aqui, porque todo mundo entra no saco de novo, e vai valer a pontuação. Aqui eu perco com certeza, porque como é uma região central, os professores pegam para completar a grade.

O problema aqui se relaciona à forma contratual destes trabalhadores, agravada pela diminuição das matrículas, o que os leva a procurar outros estabelecimentos de ensino. Desde então, a porcentagem de professores temporários ficou próxima dos índices mais altos, predominante nas escolas da periferia. Aquele professor da escola, do tempo da escola de bairro, se metamorfoseou em professor de passagem.

Por fim, cabe descrever o perfil dos alunos, com destaque para seu local de moradia. Foram analisados os alunos do ensino regular e O EJA. Em 2008, a escola tinha 445 alunos matriculados, 181 no ensino médio e 264 no EJA, estes no período noturno (SEE-CIE, 2009) ${ }^{14}$. O Mapa a seguir, Local de Moradia dos Alunos do Alves Cruz, permite visualizar a mudança espacial substantiva do alcance da escola.

Em 2008, apenas 50\% dos alunos residiam nos três distritos que circundam a escola (Perdizes, Jardim Paulista e Pinheiros). Em 1960, estes distritos respondiam por $64 \%$ dos alunos. Atualmente, esta porcentagem é atingida apenas incluindo os distritos da Lapa, da Consolação e de Alto de Pinheiros. Os demais $36 \%$ vêm de localidades mais distantes, como Raposo Tavares, Pirituba, Anhanguera, São Domingos, Campo Limpo. Para Patrícia, aluna do distrito de Raposo Tavares,

O Alves é uma escola numa localidade diferente. Tenho privilégios de estar aqui na Heitor Penteado, Pão de Açúcar, perto do Equipe, Teodoro, Cardeal, o centro é logo ali, a Lapa é do outro lado, Pinheiros. Então eu acho que o Alves tem certas regalias que outras escolas não têm.

Em termos práticos, tal mudança no raio de ação da escola é percebida entre professores e demais membros da comunidade escolar, a ponto de ter gerado a adjetivação escola de passagem. Isto se explica pela presença cada vez maior de alunos trabalhadores, que veem, na escola e sua localização, um facilitador da circulação entre o local de moradia e local de trabalho, quase sempre, nas áreas centrais da metrópole.

\footnotetext{
${ }^{14}$ Este número voltou a crescer, atingindo 697 alunos matriculados em 2010.
}

* Departamento de Geografia, Geografia Humana. Email: gfranca@usp.br 


\section{Mapa 3 - Local de moradia dos Alunos. EE. Prof. Antônio Alves Cruz Município de São Paulo, por distrito (2008)}

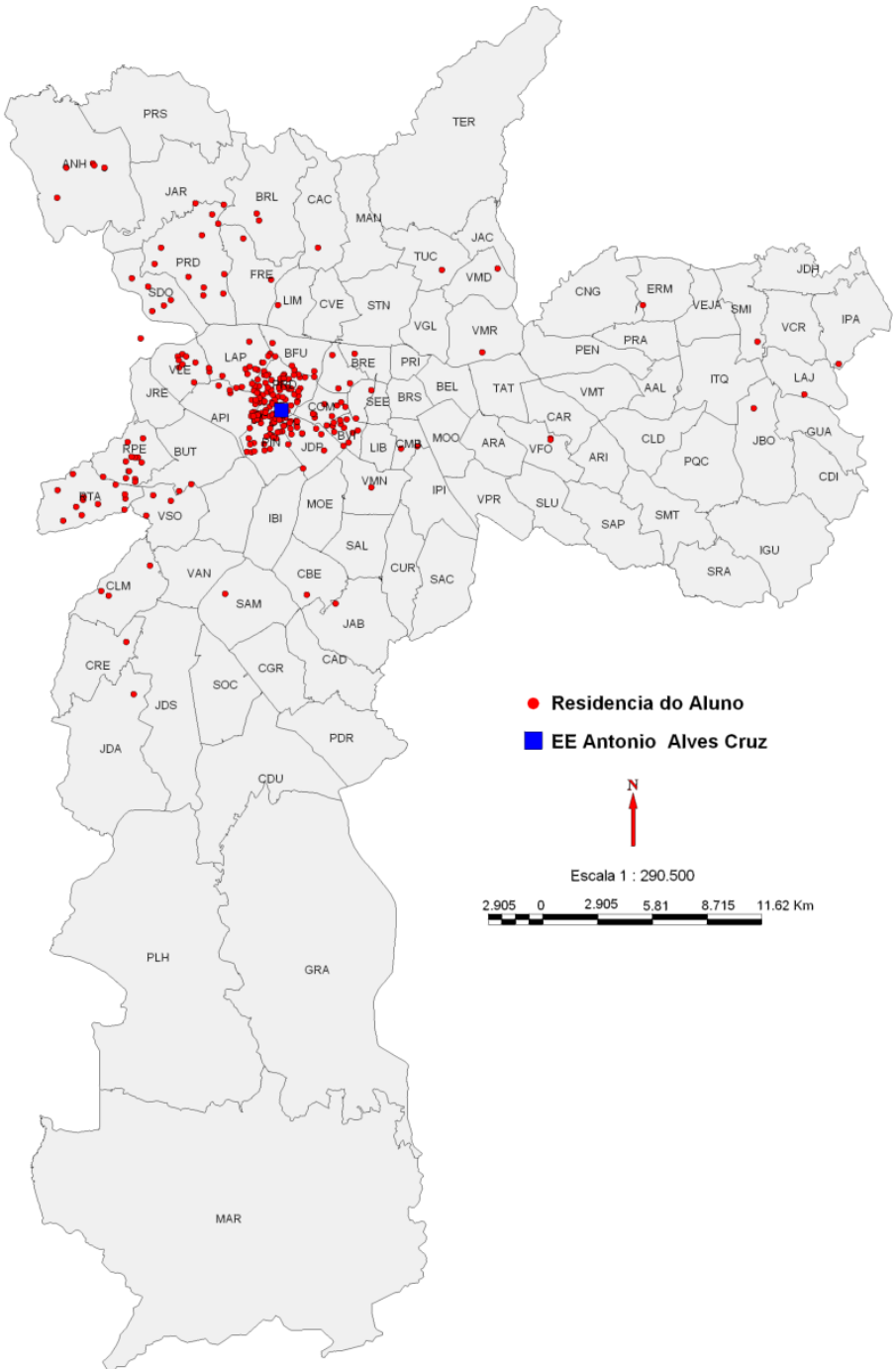

Fonte: Arquivo dos Alunos. 2008.

Num possível resumo, poder-se-ia dizer que, a partir dos anos 90, a escola teve uma alteração qualitativa, passa a ser identificada por sua comunidade como escola central ou escola de passagem. Enquanto escola de passagem atrai alunos de diversas localidades, alcançando uma centralidade metropolitana, reproduzindo internamente os interesses fragmentados da metrópole, e conflitante, representada pelos velhos e novos personagens, nas tentativas de preservá-la.

\section{CONSIDERAÇÕES FINAIS}

A pesquisa identificou o problema de um conjunto de escolas públicas dos espaços centrais e valorizados de São Paulo. A partir daí procurou explicar a situação de uma destas escolas, considerando as transformações ocorridas nas diversas escalas geográficas. $E$, neste sentido, a pesquisa apontou um caminho de análise geográfica da escola pública.

Numa escala mais geral foram identificados os limites dos investimentos educacionais e a procura do Estado, através reestruturações do sistema educacional, para contornar a demanda educacional. Tal reestruturação, como se deu na rede pública paulista, apresenta sua particularidade regional e urbana, própria da dimensão e das transformações metropolitanas de São Paulo. 
Ou seja, as políticas educacionais, sobre um quadro limitado de investimento público, procuraram adequar a oferta à geografia segregada de São Paulo. O fechamento de escolas públicas em São Paulo desperta interesses variados no curso de refuncionalização dos espaços da cidade, com investidas do poder público e do setor imobiliário na reutilização dos espaços e terrenos das antigas escolas públicas.

O problema é que tais escolas públicas também despertam interesses nos moradores das periferias e dos meandros das áreas valorizadas. Contraditoriamente, o contexto urbano que as remove também as destaca por seus atributos de localização, que aparecem inclusive nos indicadores de desempenho escolar.

No caso do Alves Cruz, pode-se ver como a reestruturação produtiva adquire sua dimensão real. Apenas neste nível pode-se apreender o drama de uma comunidade diante do esvaziamento e do fechamento de sua escola. $O$ processo externamente conduzido produz a desintegração interna entre os sujeitos da escola acelerando o desencontro com as frações valorizadas da metrópole.

A mesma escola que aparece no topo dos indicadores de desempenho, para sobreviver, teve que oferecer outras modalidades de ensino, incorporar as atividades complementares oferecidas, principalmente, por uma ONG. A escola encontra solução também no interesse de alunos de localidades mais distantes. Entretanto, a ampliação da escala de ação e a variedade de interesses no seu interior é algo estranho para uma instituição que já foi escola de bairro, centrada em cursos regulares.

\section{REFERÊNCIAS BIBLIOGRÁFICAS}

AÇÃO EDUCATIVA. Série Debates. Colóquio sobre a reorganização da rede estadual de ensino de São Paulo. São Paulo, 13 de maio 1996.

ADRIÃO, Thereza. Educação e produtividade: a reforma do ensino paulista e a desobrigação do estado. São Paulo: Xamã, 2006.

ARELARO, Lizete R. A municipalização do ensino no estado de São Paulo: antecedentes, históricos e tendências. In: OLIVEIRA, C. (Org.). Municipalização do ensino no Brasil. Belo Horizonte: Autêntica, 1999 , p. 87

BERNARDES, Adriana. A nova divisão territorial do trabalho brasileiro e a produção de informação na cidade de São Paulo (as empresas de consultoria). In: SANTOS, Milton; SILVEIRA, Maria Laura. O Brasil: território e sociedade no início do século XXI. Rio de Janeiro: Record, 2001.

BRUNO, Miguel. Acumulação de capital e crescimento econômico no Brasil: uma análise do período 1950-2006 determinantes de longo prazo. In: SICSÚ, J.; MIRANDA, P. (Org.). Crescimento econômico. Estratégias e Instituições. Rio de Janeiro: Ipea, 2009.

CARLOS, Ana Fani Alessandri. São Paulo: do capital industrial ao capital financeiro. In: CARLOS, Ana Fani Alexandre; OLIVEIRA, Ariovaldo Umbelino de (Org.). Geografias de São Paulo: a metrópole do século XXI. São Paulo: Contexto, 2004. (Volume 2).

CASTRO, Jorge Abraão de. Financiamento e gasto público na educação no Brasil: (1995 2005). Educação e Sociedade. Campinas, v. 28, n. 100, Especial, p.857-876, out. 2007.

FIX, Mariana. São Paulo cidade global: fundamentos financeiros de uma miragem. São Paulo: Boitempo, 2007.

FRANCA, Gilberto Cunha. Urbanização e educação: da escola de bairro à escola de passagem. São Paulo, 2010. Tese (Doutorado) - Universidade de São Paulo USP, 2010.

FRÚGOLI Jr., Heitor. Centralidade em São Paulo: trajetórias, conflitos e negociações na metrópole. São Paulo: Edusp, 2006.

GONÇALVES, Reinaldo. Desestabilização macroeconômica e dominação do capital 
financeiro no Brasil. En publicación: BASUALDO, Eduardo M.; ARCEO, Enrique. Neoliberalismo $y$ sectores dominantes. Tendencias globales y experiencias nacionales. CLACSO, Consejo Latinoamericano de Ciencias Sociales, Buenos Aires, Agosto, 2006.

HARVEY, David. Los límites del capitalismo y la teoria marxista. México: Fondo de Cultura Económica, 1990.

HARVEY, David. El neoliberalismo como destrucción creativa. 2007. Disponível em: <http://pt.scribd.com/doc/8913408/DavidHarvey-El-neoliberalismo-como-destruccioncreativa >. Acesso em: 2011.

HARVEY, David. O novo imperialismo. São Paulo: Edições Loyola, 2005.

INEP. Percentual do Investimento Direto em Relação ao PIB por Esfera de Governo. Disponível em:

<http://www.inep.gov.br/web/guest/estatisti cas-gastoseducacao-indicadores financeirosp.t.d._dependencia_administrativa.htm > . Acesso em: 2011.

IPEA. IPEA/DATA. Disponível: $<$ http://www.ipeadata.gov.br/>. Acesso em 20/06/2011.

LEFEBVRE, Henri, A revolução urbana. Belo Horizonte: Editora da UFMG - Humanitas, 2004.

MAIOR DESIGUALDADE escolar é em São Paulo. Folha de São Paulo, São Paulo, Cotidiano C3, 24 de dezembro de 2007.

PINTO, José Marcelino de Rezende. Limites do pacto federativo no financiamento da educação básica. Revista Adusp, Dossiê educação no Brasil, São Paulo, n. 46, 2010.
REGIÃO CENTRO-OESTE é a melhor na capital. O Estado de São Paulo, São Paulo, Caderno Vida \& Educação, 19 de março de 2009.

SÃO PAULO (Estado). SECRETARIA DE ESTADO DA EDUCAÇÃO. Educação paulista: corrigindo rumos: mudar para melhorar: uma escola para a criança, outra para o adolescente. São Paulo: SEE, [1995].

SÃO PAULO, 454 anos. Região de Pinheiros é a melhor de São Paulo. Folha de São Paulo, São Paulo, Especial C1, p.6, 26/01/2008.

SARESP. Disponível em:

$<$ http://saresp2009.edunet.sp.gov.br/pdf/02 Apresentacao final.pdf $>$. Acesso em 30/03/2010.

SEABRA, Odete de Carvalho. São Paulo: a cidade, os bairros e a periferia. In: CARLOS, Ana Fani Alexandre; OLIVEIRA, Ariovaldo Umbelino de (Org.). Geografias de São Paulo: representação e crise da metrópole São Paulo: Contexto, 2004. (Volume I).

SEE/CIE. Cadastro das Escolas do Estado de São Paulo. São Paulo: SEE/CIE, 2010.

SMDU. SECRETARIA MUNICIPAL DE DESENVOLVIMENTO URBANO. $<$ http://www.prefeitura.sp.gov.br/cidade/sec retarias/desenvolvimento urbano/dados esta tisticos >. Acesso em 20/06/2011.

TORRES, Haroldo. Medindo a segregação. In: MARQUES, Eduardo; TORRES, Haroldo. São Paulo: segregação, pobreza e desigualdade social. São Paulo: Editora SENAC, 2005.

VASCONCELlOS, Patrícia Meira de. Projeto na escola: novas trilhas para o ensino médio. São Paulo, 2004. Dissertação (Mestrado) Pontifícia Universidade Católica de São Paulo - PUC, 2004. 